\title{
¿Reparar la esclavitud en Colombia? Movilización del derecho en un contexto multicultural
}

\author{
Repairing Slavery in Colombia? Mobilization \\ of Law in a Multicultural Context*
}

\author{
Elisabeth Cunin ${ }^{* *}$ \\ Unité de Recherches Migrations et Société (Urmis), Institut de Recherche pour le Développement \\ Centre International de Recherches sur les Esclavages et les Post-esclavages (Ciresc), Francia
}

D0I: $10.22380 / 2539472 X .1176$

\section{RESUMEN}

En Latinoamérica, la abolición de la esclavitud y el acceso a la ciudadanía van de la mano. Quienes descienden de esclavos conocen un proceso de integración ambiguo entre una igualdad formal y la permanencia de jerarquías sociorraciales. El giro multicultural de 1980-1990 enfatizó la necesidad de reconocer las diferencias y definió a las poblaciones afrodescendientes como un grupo étnico. En este contexto, ¿qué lugar ocupan las reparaciones de la esclavitud? Con base en la movilización del derecho, este artículo estudia dos sentencias de la Corte Constitucional sobre las reparaciones de la esclavitud enfocándose en tres temas: la articulación entre lógicas políticas y jurídicas de acción; el papel de la historia en el tribunal y la redefinición de las relaciones entre pasado y presente; y el racismo estructural en la propia administración judicial. La conclusión abre la reflexión sobre las transformaciones del marco multicultural reveladas por las reparaciones.

Palabras clave: reparaciones, esclavitud, derecho, historia, racismo.

\begin{abstract}
In Latin America, the abolition of slavery and access to citizenship go hand in hand. Descendants of slaves experienced an ambiguous integration process between formal equality and the permanence of socio-racial hierarchies. The "multicultural turn" of 1980-1990 emphasized the need to recognize differences and defined Afro-descendant populations as an ethnic group. In this context, what place do reparations for slavery occupy? This article studies two judgments of the Colombian Constitutional Court on reparations for slavery, focusing on three issues: the articulation between political and legal logics of action; the role of history in court and redefinition of past-present relations; structural racism in the judicial administration itself. The conclusion opens the reflection on the transformations of the multicultural framework revealed by the reparations.
\end{abstract}

Keywords: reparations, slavery, law, history, racism.

Este artículo fue escrito originalmente en francés, en el marco del programa ANR Repairs (Francia) "Reparaciones, compensaciones e indemnizaciones por la esclavitud (Europa-América-África), siglos XIX-XX", coordinado por el Centre International de Recherches sur les Esclavages et les Post-esclavages (Ciresc). La traducción del francés al español fue realizada por Isabel Marenco (Costa Rica).

elisabeth.cunin@ird.fr / https://orcid.org/0000-0003-3988-5435 


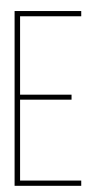

n la investigación social, el tema de las reparaciones se ha desarrollado a escala global, especialmente después de la Segunda Guerra Mundial, la creación de la primera jurisdicción penal internacional en el juicio de Núremberg y el surgimiento de la noción jurídica de crimen contra la humanidad. También se ha expandido a propósito de la expoliación de tierras a los pueblos originarios, el internamiento de estadounidenses de origen japonés durante la guerra y, más recientemente, con las comisiones de justicia y verdad destinadas al retorno a la democracia.

Estas últimas han tenido un papel fundamental en América Latina y han sido objeto de múltiples estudios, en particular en relación con dinámicas sociales de democratización y justicia transicional. Hoy se alude a las reparaciones en casos tan diversos como aquellos referidos a violencia política, daños relacionados con la atención médica o afectaciones ambientales. Recientemente, el presidente de México, Andrés Manuel López Obrador, provocó un nuevo debate al reclamar al Estado español reparaciones por las consecuencias de la conquista (ver Urrutia 2019). En términos generales, las reparaciones tienen como objetivo poner fin a las injusticias históricas (colonización, esclavitud, crímenes contra la humanidad, etc.), cuyos efectos aún pesan en el presente. Más allá de la distinción entre víctimas y acusados, se refieren a toda la comunidad política y a la capacidad misma de una sociedad para reconocer la existencia de daños que no han sido indemnizados.

Este artículo se centra exclusivamente en las reparaciones relacionadas con la esclavitud en el caso colombiano. Su origen se puede rastrear a partir de la abolición de la esclavitud en los Estados Unidos durante el periodo de la Reconstrucción (1865-1877), cuando se propuso dar " 40 acres y una mula” a los descendientes de esclavos. La cuestión de las reparaciones es recurrente en el debate militante e intelectual estadounidense y, más recientemente, ha venido creciendo en el Caribe (Comisión de Reparación de la Caricom). También se evoca episódicamente en otros lugares - en particular en Gran Bretaña, Francia, Mauricio, Brasil y Nigeria-, aunque hasta ahora no ha llegado a ser una referencia movilizadora. La Conferencia de Durban, preparada por la Organización de las Naciones Unidas (ONU) en 2001, le dio gran publicidad al tema, pero las reparaciones por la esclavitud no se incluyeron en la declaración final, una señal de la ausencia de consenso internacional al respecto.

En Colombia, en la década del 2000, el tema de las reparaciones relacionadas con la esclavitud se abordó en una serie de cinco libros coordinados por Claudia Mosquera Rosero-Labbé, profesora del Departamento de Trabajo Social en la Universidad Nacional de Colombia (Mosquera, Pardo y Hoffmann 2002; Mosquera y Barcelos 2007; Mosquera y León 2009; Mosquera, Laó-Montes y Rodríguez 
2010; Mosquera, León y Rodríguez 2009). Si bien tratan de múltiples temáticas relativas a la esclavitud y sus consecuencias y no solamente de las reparaciones, estas publicaciones contribuyeron a visibilizar la cuestión en Colombia en la década del 2000. Para continuar el debate abierto por dicha colección, me he planteado aquí la siguiente pregunta: ¿cómo se articulan las reparaciones con las lógicas multiculturales desarrolladas en los años noventa?

En específico, este artículo aborda dos casos de reivindicaciones contemporáneas de reparaciones relacionadas con la esclavitud en Colombia ${ }^{1}$, que involucran la movilización del derecho y la intervención de la Corte Constitucional. El primero es un reclamo de inconstitucionalidad contra la ley de abolición de la esclavitud del 21 de mayo de 1851 (Fallo C-931/09 de la Corte Constitucional, 10 de diciembre de 2009, "Demanda de inconstitucionalidad contra la Ley del 21 de mayo de 1851 sobre la libertad de esclavos”). El segundo es una acción de tutela para defender un derecho de propiedad obtenido en compensación de la esclavitud (Decisión de la Corte Constitucional T-601/16, 2 de noviembre de 2016, “Conservación de la identidad y protección de la vida de comunidades afrocolombianas”).

La dinámica de la reivindicación de los derechos, la judicialización de la política y el activismo legal han sido significativos en América Latina desde la década del 2000 (Epp 2013; Feoli 2016; Herrera 2015), particularmente en Colombia. La "democracia constitucional” de este país es antigua: comienza a fines del siglo XIX con la Constitución de 1886 y adquiere nuevas dimensiones con la declaratoria del Estado social de derecho en la Constitución Política de 1991, que también buscaba contribuir al fin del conflicto armado y reformular el contrato social (Cepeda 2004; Lemaitre 2009). En un contexto de débil legitimidad de los poderes Ejecutivo y Legislativo, la Corte Constitucional colombiana se cita como ejemplo por su influencia y la naturaleza innovadora de sus posiciones. Ambos rasgos se expresan especialmente en el reconocimiento legal de la multiculturalidad de la sociedad y el Estado.

El derecho se ha vuelto central en las movilizaciones sociales contemporáneas y la demanda de reparaciones por la esclavitud encaja perfectamente en este marco. Los casos estudiados nos permitirán comprender mejor la lógica de producción del derecho y la manera como esta producción combina herramientas jurídicas, compromiso político, instrumentalización de la historia y reactualización del racismo. Para ello, me inspiro en una antropología y una sociología del derecho atentas a la propia construcción del derecho (Dupret 2006; Israel 2008),

1 También hay que subrayar que el tema de las reparaciones a las víctimas del conflicto armado está muy presente en Colombia, en particular a partir de la Ley 1448 de 2011. Estas reparaciones incluyen una dimensión étnica (ver, por ejemplo, López et al. 2019) que solo remite de manera marginal a la cuestión de las reparaciones de la esclavitud (Codhes 2017). 
que lo analizan en contexto y en acción y toman sus prácticas sociales de producción como objetos de estudio (Cuéllar 2000).

Después de presentar los casos, me enfocaré en la articulación entre lo jurídico y lo político en las dos sentencias de la Corte Constitucional². Así mismo, analizaré el recurso al derecho considerando que tiene una dimensión política que se revela en la transformación de la legitimidad de la política y de los modos de gobierno (Commaille y Dumoulin 2009, 65; Garapon 2008, 14). En ese sentido, con el análisis de los argumentos de las dos sentencias, mostraré cómo un discurso y un compromiso políticos atraviesan la acción de los jueces. Luego examinaré el lugar otorgado a la historia en la construcción del discurso jurídico.

De otra parte, las reparaciones por la esclavitud presuponen una compensación por un acto cometido en el pasado. Conducen a "poner la historia en un tribunal” para juzgar hoy los daños causados en una época anterior (Ogletree 2003, 1055). Si la historia es ahora justiciable, me pregunto entonces, ¿qué lugar le dan los jueces y las juezas a la narrativa histórica en su defensa jurídica? Finalmente, me detendré en la contribución del derecho a la identificación del racismo: ¿aportan las sentencias herramientas nuevas para denunciar la discriminación, en particular la estructural? ¿O más bien la revelan en las propias prácticas jurídicas? ¿Qué consecuencia tiene esta discriminación en el acceso al derecho? La conclusión me permitirá reflexionar sobre los vínculos entre las reparaciones y el multiculturalismo: ¿estamos presenciando una transformación, una crítica, una superación del giro multicultural de los años ochenta y noventa en las Américas?

\section{Las dos sentencias de la Corte Constitucional}

La Corte Constitucional se creó en 1991 como parte de los cambios acaecidos en Colombia con el establecimiento de una Asamblea Nacional Constituyente (1989) y una nueva Constitución Política (1991). Esta entidad judicial es garante de la integridad y soberanía de la Constitución y simboliza el espíritu de pluralismo, participación, igualdad y respeto a la dignidad humana, promovido por los constituyentes (Cepeda 2004, 166). La Constitución de 1991 amplió el alcance de la

2 En el artículo se usará la sigla SCC para abreviar "sentencia de la Corte Constitucional de Colombia". [N. de la E.] 
acción pública de inconstitucionalidad al hacerla accesible a la ciudadanía en general. También creó la acción de tutela, mecanismo que permite a cualquier ciudadano o ciudadana acudir a la Corte Constitucional si considera que no se han respetado sus derechos fundamentales.

\section{Demanda de inconstitucionalidad contra la ley de abolición de la esclavitud del 21 de mayo de $1851^{3}$}

En 2009, Antonio Eduardo Bohórquez Collazos, abogado y profesor de derecho en Barranquilla, presentó una demanda de inconstitucionalidad en la Corte Constitucional contra la ley de abolición de la esclavitud del 21 de mayo de 1851. Él afirmaba que la ley había ignorado el principio de la dignidad humana y había introducido una “omisión legislativa” que compensaba a los antiguos amos, pero no a los nuevos libres por los daños materiales e inmateriales sufridos. Para el demandante, la ley no había sido derogada y sus efectos desiguales no habían sido corregidos; por lo tanto, estaba en contradicción con la Constitución de 1991. La Corte Constitucional, presidida por la magistrada María Victoria Calle Correa ${ }^{4}$, se declaró incompetente para responder a la solicitud de Bohórquez Collazos: la Ley de 1851 ya no estaba vigente y ya no producía efectos en el orden jurídico contemporáneo. El contenido normativo de la Ley de 1851 se consideraba modificado por normas posteriores - caso particular de la Constitución de 1853 que elevó la prohibición de la esclavitud al estatus constitucional- o se excedía debido a su ubicación histórica — procedimientos de abolición limitados en el tiempo-. Para justificar esta decisión, la Corte se basó primero en un argumento jurídico y volvió a las condiciones de definición de su jurisdicción en relación con una acción de inconstitucionalidad, la delimitación de los efectos legales de una ley y la derogación de las normas, en referencia a varias sentencias anteriores.

Sin embargo, aunque no se considerara competente, la Corte acompañó su sentencia con una denuncia de las desigualdades sociorraciales y la inacción del Estado, no rechazó la idea de las reparaciones e incluso mencionó las medidas que debían tomarse para "reparar" las consecuencias de la esclavitud

3 SCC C-931 del 10 de diciembre 2009, "Demanda de inconstitucionalidad contra la Ley del 21 de mayo de 1851 sobre la libertad de esclavos". Esta sentencia fue objeto de un artículo de Viridiana Molinares Hassan (2013), quien la considera un ejemplo del nuevo constitucionalismo latinoamericano y el respeto por los derechos.

4 Magistrada de la Corte Constitucional en el periodo 2009-2017. Apoyada por el expresidente Álvaro Uribe, es sin embargo considerada una magistrada independiente y liberal, en particular por haberse pronunciado a favor del derecho al aborto y del matrimonio entre personas del mismo sexo, a diferencia del expresidente. 
(SCC C-931/09, párr. 18). Además, adjunta a la sentencia iba una apelación (salvamento de voto) de los jueces Juan Carlos Henao Pérez ${ }^{5}$ y Luis Ernesto Vargas Silva ${ }^{6}$, quienes refutaban las conclusiones de María Victoria Calle Correa y consideraban que la Corte era competente para responder a la solicitud de Bohórquez Collazos.

\section{Acción de tutela para defender un derecho de propiedad obtenido en compensación de la esclavitud ${ }^{7}$}

En el segundo caso estudiado, Edelmira Ortega de Marrugo, como miembro de la comunidad de copropietarios de la hacienda Arroyo Grande, presentó en enero de 2014 una acción de tutela contra varias administraciones públicas (la Inspección de Policía de Arroyo Grande, el Ministerio del Interior, el Instituto Colombiano de Desarrollo Rural [Incoder], la Procuraduría General de la Nación, la Personería Distrital de Cartagena, la Fiscalía General de la Nación, entre otras) que no intervinieron para proteger el derecho de propiedad de la comunidad de Arroyo Grande, expulsada de sus tierras por el conflicto armado. Ortega denunció que las familias que habían sido históricamente propietarias de predios fueron forzadas a desplazarse y que las administraciones públicas no intervinieron para proteger sus derechos.

La región donde se localiza la hacienda, en la costa caribe, ha estado marcada por el conflicto colombiano y hoy es objeto de fuertes intereses de desarrollo (turismo, minería). Sus terrenos abarcan una extensión de casi 18.000 hectáreas, estratégicamente ubicadas entre Cartagena y Barranquilla y atravesadas por la carretera que une a las dos ciudades. La tutela se basa en una reivindicación sin precedentes: la tierra fue otorgada colectivamente a 113 familias afrocolombianas en 1897 en compensación por la esclavitud ${ }^{8}$. En noviembre de 2016, la Sala

5 Fue magistrado del Consejo de Estado, asesor de la Procuraduría General de la Nación y presidente de la Corte Constitucional (2009-2010). En 2012 fue elegido como rector de la Universidad Externado de Colombia.

$6 \quad$ Fue magistrado de la Corte Constitucional (2009-2017) y designado su presidente en 2014. Presidió la Sala Especial de Seguimiento creada para la ejecución de la Sentencia Estructural T-025 de 2004 que declaró un estado de cosas inconstitucional en materia de desplazamiento forzado. Desde el 2017 ocupa el cargo de relator sobre derechos de los migrantes en la Comisión Interamericana de Derechos Humanos.

7 SCC T-601 del 2 de noviembre 2016, “Conservación de la identidad y protección de la vida de comunidades afrocolombianas".

8 Ver también el caso de Guamal, estudiado por Sofía Lara Largo (2016) en su tesis doctoral. 
Quinta de Revisión de la Corte Constitucional, que estudia las tutelas seleccionadas por los jueces y que entonces era presidida por la magistrada Gloria Stella Ortiz Delgado ${ }^{9}$, falló a favor de la demandante al ordenar a la Agencia Nacional de Tierras - anteriormente Incoder- que procediera a aclarar los derechos de propiedad de las tierras de Arroyo Grande (delimitación geográfica, validación de títulos de propiedad), con prioridad sobre los "derechos de las comunidades étnicas afrodescendientes, en virtud de la especial protección constitucional de que gozan, que, como se indicó, redunda en el enriquecimiento cultural de toda la nación colombiana” (resoluciones 2 y 3).

La Sentencia T-601/16 (“Antecedentes”, párr. 9) presenta la atribución del título a 113 descendientes de esclavos y esclavas como forma de "compensación..." o pago por los años de trabajo forzado (Auto 530 de la Corte Constitucional, 17 de noviembre de 2015). Esta es la primera vez que se identifica y moviliza un texto histórico que otorga indemnizaciones a descendientes de esclavos para justificar un derecho contemporáneo de propiedad colectiva. Además, la sentencia se refirió a la discriminación estructural contra las poblaciones afrodescendientes.

Por lo tanto, el acceso a la tierra no se fundamentó aquí —al menos inicialmente - en la Ley 70 de 1993, la herramienta central del multiculturalismo colombiano (Hoffmann 2004). Esta otorga la propiedad colectiva de la tierra a las poblaciones definidas como comunidades negras, que ocupen "tierras baldías en las zonas rurales ribereñas de los ríos de la Cuenca del Pacífico” y se identifiquen por sus “prácticas tradicionales de producción”. La tutela de 2016 abre así un precedente notable en el contexto colombiano: reconoce un derecho territorial colectivo para las poblaciones afrodescendientes que no se basa en la legislación multicultural vigente. Un criterio histórico (obtener un título de propiedad como descendientes de esclavas y esclavos a fines del siglo XIX) reemplaza aquí los criterios administrativos (tierra vacía), geográficos (Pacífico, ríos) y antropológicos (prácticas tradicionales).

\section{La dimensión política del derecho}

Los dos casos estudiados se basan fundamentalmente en la referencia a herramientas jurídicas: incumplimiento de la ley de abolición de la esclavitud a la luz

$9 \quad$ Magistrada de la Corte Constitucional desde el 2014, de la cual fue presidenta hasta 2020. Ocupó cargos en el Consejo de Estado, el Consejo Superior de la Judicatura y la Fiscalía General de la Nación. 
de la Constitución de 1991 y violación de los derechos de propiedad denunciada mediante la tutela de Arroyo Grande. Sin embargo, el discurso jurídico también estuvo acompañado por posturas más políticas sobre las consecuencias de la esclavitud, el papel del Estado y las desigualdades de la sociedad colombiana. En este contexto, se propone aquí analizar los mecanismos de esa superposición entre lo jurídico y lo político en los propios textos de la Corte.

La Sentencia C-931/09 sobre la inconstitucionalidad de la ley de abolición de 1851 solicita la opinión de varios actores con posicionamientos múltiples y contradictorios, en un excelente ejemplo de un debate político abierto por el propio espacio jurídico ${ }^{10}$. Por un lado, los ministerios de Cultura, del Interior y de Justicia, la Academia Colombiana de Jurisprudencia, académicos de las universidades del Cauca, Icesi y Santiago de Cali, y el ciudadano Jack J. Smith ${ }^{11}$ rechazan la solicitud de Antonio Eduardo Bohórquez Collazos. Los argumentos presentados son los siguientes: 1) la solicitud no cumple con las condiciones para la revisión de la constitucionalidad de una medida anterior a la Constitución de 1991, tal como se define en la SCC C-571/2004; 2) la ley de manumisión no tiene efectos legales hoy porque sus efectos ya han tenido lugar y porque fue revocada por disposiciones constitucionales en 1858, 1863, 1886 y 1991; 3) al suprimir la esclavitud, la ley de manumisión ha restaurado la dignidad de los antiguos esclavos y no es el origen del racismo; 4) los derechos reivindicados por la solicitud de inconstitucionalidad no existían en ese momento. Estos actores consideran que el cuestionamiento de la Ley de 1851 cae dentro del dominio político, no del jurídico, particularmente la aplicación del artículo 13 de la Constitución de 1991 sobre la igualdad y la garantía de no discriminación.

Por otro lado, tres organizaciones apoyan la solicitud de Bohórquez Collazos. El Proceso de Comunidades Negras (PCN) ${ }^{12}$ afirma que los efectos de la Ley de 1851 todavía son palmarios y que la esclavitud es una realidad actual para las poblaciones afrocolombianas. El Centro de Estudios de Derecho, Justicia

10 De su lado, la SCC T-601/16 incluye las respuestas de las administraciones públicas cuestionadas por la tutela. La naturaleza misma de la acción de tutela estudiada, que acusa a las administraciones, las dispone en una lógica de defensa de sus propias prácticas y no de discusión de un problema público.

11 La sentencia no especifica su estatus ni la razón de su audiencia. Jack J. Smith May, originario de la isla de San Andrés, fue auxiliar judicial en la Corte Constitucional en 2009, antes de trabajar en el Ministerio de Relaciones Exteriores.

12 El PCN es una de las principales organizaciones afrocolombianas, muy activa en particular en la dinámica de organización de las poblaciones negras y su acceso a la tierra en el marco de la Ley 70 de 1993. 
y Sociedad (DeJusticia) ${ }^{13}$ y el Observatorio de Discriminación Racial ${ }^{14}$ también $^{2}$ consideran que la Ley de 1851 todavía está vigente formalmente. Al referirse a la esclavitud como un crimen, ambos señalan que los efectos de esta se manifiestan hoy en la continuidad de la discriminación y la marginación social que padecen dichas poblaciones. Las tres organizaciones consideran que la Corte Constitucional tiene el deber de exigir una política de reparaciones colectivas e integrales que afirme la identidad del grupo étnico, genere condiciones de igualdad efectiva, responda a las violaciones de los derechos humanos y denuncie la responsabilidad del Estado.

La SCC C-931/09 favoreció ampliamente la expresión de múltiples opiniones sobre los efectos de la ley de abolición; en este sentido, desempeñó un papel decisivo en el surgimiento de un debate plural y abierto sobre la esclavitud. Aquí es interesante constatar que las posiciones antagónicas se refieren a un equilibrio invertido entre las lógicas jurídicas y políticas. Por un lado, para los actores que rechazaron la inconstitucionalidad de la ley de abolición, los argumentos están estrictamente en un registro jurídico y consideran que una discusión sobre la ley de abolición y sus efectos es una decisión política. Por otro lado, quienes abogan por aceptar el reclamo de inconstitucionalidad confían en un discurso político (la esclavitud como un crimen contra la humanidad, el racismo contemporáneo, el deber del Estado de reparar la esclavitud) para justificar una acción jurídica. De hecho, la Corte considera este argumento como "circular” (SCC C-931/09, “Consideraciones y fundamentos”, tít. 4.4.2) porque se basa en una petición de principio, que parte de la conclusión a la que pretende llegar.

En última instancia, la Corte Constitucional se declara incompetente para responder a la solicitud de Antonio Eduardo Bohórquez Collazos, ya que la Ley de 1851 no está vigente y no tiene ningún efecto en el orden jurídico contemporáneo. El contenido normativo de esta ley se considera modificado por normas posteriores - este es el caso particular de la Constitución de 1853, que eleva la prohibición de la esclavitud al estatuto constitucional- o caduco porque se encuentra históricamente situado.

Adicionalmente, la SCC C-931/09 integra una apelación de los magistrados Juan Carlos Henao Pérez y Luis Ernesto Vargas Silva, quienes no comparten las conclusiones de la Corte y la obligan a presentar una aclaración de la sentencia

13 DeJusticia es una ONG de investigación-acción enfocada en la promoción de los derechos humanos a través de la producción de conocimiento, capacitación, propuestas de políticas públicas o litigios estratégicos. Ver su web oficial: https://www.dejusticia.org/ 
(“aclaración de voto"). Por un lado, sobre la base de muchas sentencias anteriores, consideran que la Corte es competente para responder a la solicitud de inconstitucionalidad emitida por Bohórquez Collazos y, por otro lado, que es necesario profundizar la cuestión de la vigencia actual de la ley de abolición del 21 de mayo de 1851 y sus efectos legales. Su argumento es doble: esta ley nunca ha sido derogada explícitamente y todavía tiene efectos legales, precisamente relacionados con la omisión denunciada, el pago de indemnizaciones a los antiguos amos y no a los antiguos esclavos. Leída a la luz de la Constitución de 1991, la Ley de 1851 no permitió garantizar los mismos derechos a los amos y a los esclavos, y este efecto negativo de la norma no fue compensado.

Este llamado se convierte en una plataforma para las reparaciones relacionadas con la esclavitud. Los dos magistrados se refieren a la noción de reparaciones históricas que remite a la existencia de

hechos ocurridos en el pasado, que han producido daño severo a grupos de población específicos o determinables, que, a pesar del paso del tiempo (décadas o siglos) y la certeza en cuanto a su naturaleza antilegal e ilegal, no han sido objeto de medidas institucionales para corregir sus consecuencias. (Anexo a SCC C-931/09, “Salvamento de voto”, punto 35)

Para Henao Pérez y Vargas Silva, la Corte Constitucional perdió la “oportunidad histórica” de reconocer, conforme a la Constitución de 1991, el crimen de esclavitud y sus consecuencias y de exigir las reparaciones para las víctimas de la esclavitud en Colombia. Su llamamiento parte de la necesidad (política, histórica, moral) de introducir reparaciones para justificar la inconstitucionalidad de la ley de abolición. Por su parte, María Victoria Calle Correa proporciona una respuesta estrictamente jurídica a esta apelación; sin embargo, afirma repetidamente que la incompetencia de la Corte para decidir sobre la inconstitucionalidad de la ley de abolición no significa que relativice los efectos devastadores de la esclavitud y el racismo. Aun si estos "no son consecuencias jurídicas controlables” de la ley de abolición (anexo a SCC C-931/09, “Aclaración de voto”, punto 14), sí afectan directamente los derechos de las poblaciones afrocolombianas.

Luego, la Corte hace un llamado al reconocimiento del crimen de la esclavitud, a la reconstrucción de la memoria, a la adopción de las medidas necesarias para reducir las desigualdades, a la aplicación del principio de consulta previa resultante del Convenio 169 de la Organización Internacional del Trabajo (OIT), a la lucha para combatir las prácticas racistas pasadas y presentes. Estas reivindicaciones no fueron necesarias, ya que la Corte dictaminó jurídicamente sobre su incompetencia; al mismo tiempo, transmiten un fuerte mensaje al Estado y a la sociedad colombiana. Aquí se perfilan dos configuraciones de la dimensión 
política de la Corte Constitucional: mientras que la apelación de Henao Pérez y Vargas Silva tiende a defender un punto de vista político con el uso de herramientas jurídicas, la sentencia de Calle Correa se limita al marco jurídico, al tiempo que introduce un posicionamiento político en su margen.

\section{Cuando el juez deviene historiador}

En las dos sentencias de la Corte Constitucional, la historia tiende a ser convocada como un "elemento de la prueba”, junto con las herramientas jurídicas. Las sentencias cuestionan la relación implícita entre el derecho y la historia como disciplina científica ${ }^{15}$. Los registros que alimentan las dos sentencias contienen muchos elementos históricos. Producen un efecto cognitivo real al aportar una contribución erudita a la historia de la esclavitud y de la posesclavitud. La ley de abolición del 21 de mayo de 1851 está integralmente publicada y ha sido ampliamente comentada. A este respecto, puede plantearse entonces la cuestión del nivel de autoridad y legitimidad de la Corte Constitucional para elaborar una narrativa histórica que justifique una decisión de orden jurídico.

La SCC C-931/09 (n. 24) cita una bibliografía consecuente de veintiséis referencias históricas, se basa en numerosas obras de especialistas y contiene múltiples notas al pie de página que especifican su argumentación. Su narrativa histórica se sitúa en el registro de la cientificidad sin cumplir con las condiciones de esta: falta de información sobre autores y autoras, falta de presentación de la metodología y las fuentes, falta de validación por parte de pares. Si bien este recurso a la historia se presenta primero en una lógica de contextualización de la Ley de 1851 (SCC C-931/09, “Aclaración de voto”, introducción) que aparece gradualmente como una forma de comprender mejor los eventos pasados, luego se convierte en una verdadera lección de historia que ya no solo trata las leyes (la primera abolición de Antioquia, la Ley de 1851, constituciones sucesivas), sino que se extiende a la influencia de Haití, a la posición de Simón Bolívar, a una comparación con los Estados Unidos, al papel de los cimarrones, a las tensiones raciales a principios del siglo XIX.

Por su parte, la SCC T-601/16 propone una "breve reseña” (“Consideraciones de la Corte Constitucional”, punto 30) de la situación de las poblaciones afrocolombianas. Esta, sin embargo, se extiende desde la llegada de Cristóbal Colón

15 Ver Audoin-Rouzeau (2016), sobre Ruanda. 
hasta nuestros días y no incluye ningún trabajo especializado, a excepción del de Manuel Zapata Olivella. Toma ciertas posiciones generales afirmativas y definitivas ${ }^{16}$ sin datos históricos de referencia. Es de esta manera, por ejemplo, como la sentencia se remonta a la ley de abolición de la esclavitud. Si bien menciona la SCC C-931/09, es muy crítica con respecto a la Ley de 1851 cuando dice que las promesas de libertad no fueron efectivas de inmediato y solo se garantizó la libertad física (“Consideraciones de la Corte Constitucional”, puntos 35-36). La sentencia de 2009, en cambio, adoptó una postura más neutral, que no implicó la evaluación de las consecuencias históricas de la ley y se limitó a medir su valor jurídico.

Estas dos sentencias ofrecen opiniones contrastantes sobre el mismo evento histórico fundamental, al tiempo que presentan sus puntos de vista como certezas. Ambos textos contienen gran cantidad de alusiones a un vocabulario de autoridad y afirmación (“es evidente”, “es claro”). Se inscriben en el campo del conocimiento en el que las controversias y desacuerdos son muy comunes. Pero la presentación de síntesis históricas sin asperezas ni polifonía cuestiona las modalidades de su elaboración y la imposición de visiones unívocas de la historia que, además, entran en contradicción entre las dos sentencias. En términos más generales, las sentencias mencionadas plantean la cuestión del uso de disciplinas científicas, como la historia y la antropología, en la producción de normas jurídicas (Bocarejo 2011). Como Bruno Latour (2002, 252-255) nos recuerda, los registros de enunciación del jurista y del investigador son radicalmente diferentes: el primero produce lo justo, dice el derecho, basándose en la jurisprudencia; el segundo busca la verdad recolectando hechos fundamentados en la experiencia — del laboratorio, de la etnografía, de los archivos-. Al introducir otras disciplinas en el proceso jurídico, la Corte transforma la ciencia en experticia que enuncia un juicio de autoridad, capaz de “tener la última palabra” (Latour 2002, 252), y sustenta parte de su deliberación en un corpus no jurídico. Si la historia ahora es justiciable, queda por ver si se juzga la historia con herramientas jurídicas o si los tribunales reescriben la narrativa histórica producida por los historiadores.

Viridiana Molinares (2013) insiste en la naturaleza innovadora de la SCC C-931/2009, que introduce una larga presentación histórica, acompañada de algunas referencias literarias, y permite una contextualización sociohistórica del derecho, que a menudo es muy abstracto. Esta apertura, sin embargo, también da la impresión de una cierta instrumentalización de la historia al servicio de la demostración legal. Diana Bocarejo (2011), a través de su estudio de las

16 Las poblaciones afrodescendientes no tuvieron los mismos derechos que las otras en el periodo republicano ("Consideraciones de la Corte Constitucional", punto 30); las poblaciones afrodescendientes tienen un concepto distinto de la tierra ("Consideraciones de la Corte Constitucional", punto 69). 
sentencias de la Corte Constitucional sobre las poblaciones indígenas, demostró claramente la lógica de la distinción entre "comunidades con cultura” y "comunidades sin cultura”: solo las primeras, capaces de aprovechar su ancestralidad, pudieron reclamar sus derechos territoriales. Del mismo modo que la Corte tiende a construir un otro étnico territorializado, en nombre de su supuesta competencia antropológica, se podría decir que produce una narrativa histórica global y lineal que reescribe los textos de los historiadores, aunque estos sean múltiples y contradictorios. Ya no se trata de partir de una premisa actual (racismo, desigualdades, desplazamiento forzado, violencia) para poner la historia frente a un tribunal, sino de producir una narrativa histórica al servicio de la herramienta jurídica.

\section{Discriminación estructural: argumentación jurídica, disfunción administrativa y acceso a los derechos}

La SCC T-601/2016 sobre Arroyo Grande aborda un nuevo desafío, el de la discriminación estructural, que cuestiona directamente el funcionamiento mismo de las instituciones, más allá de los actos individuales. Este tema no fue presentado por la demandante; es un elemento de la estrategia propia de la magistrada a cargo de la tutela. La sentencia muestra un argumento jurídico en construcción, pero más que todo es una ilustración empírica de esta discriminación estructural en la propia burocracia estatal, en particular jurídica.

La Corte Constitucional denuncia una situación de discriminación estructural $^{17}$ que conduce a la vulnerabilidad del derecho fundamental a la identidad étnica y cultural de la comunidad afrodescendiente de Arroyo Grande. Sin que sea posible detectar - por parte de las autoridades - un rechazo explícito a la validación de una escritura de propiedad, según la Corte es indiscutible que los actores menos dotados de capital (social, económico, político), que a menudo se confunden con las poblaciones negras en la región, también son aquellos cuyos derechos son los menos respetados y garantizados. Un ejemplo es la incertidumbre

17 El racismo individual trata más sobre la intención y el posicionamiento ideológico de las personas; la discriminación estructural trata sobre prácticas y orientaciones consideradas como sistémicas, remite a una forma de racismo sin racista y racismo sin raza (Dunezat y Gourdeau 2016). 
administrativa que caracteriza el derecho de propiedad (pérdida o no renovación de títulos de propiedad, inexactitud en la delimitación de la tierra).

¿Cuáles son los argumentos de la Corte Constitucional para calificar el caso de Arroyo Grande como uno de discriminación estructural? La Corte se basa principalmente en la jurisprudencia, en referencia a seis sentencias dictadas entre 1994 y 2014. Dos tratan casos de discriminación — por orientación sexual para la SCC C-481/1998 y contra las trabajadoras sexuales para la SCC T-629/2010_, pero no mencionan el tema de la discriminación estructural. Las otras sentencias lo abordan directamente: la situación de discriminación sexual y la referencia a la "estructura discriminatoria” de la administración (SCC T-098/1994); discriminación racial en la universidad y mención de "patrones clasistas, sexistas o racistas [que] persisten en las estructuras jurídicas, sociales, institucionales” (SCC T-691/2012); análisis en profundidad de la noción de discriminación estructural para personas con discapacidad (SCC C-671/2014); evocación de "patrones de discriminación estructural” debidos al incumplimiento de la consulta previa de las poblaciones negras (SCC T-969/2014).

Esta dinámica muestra hasta qué punto la Corte está nuevamente en la frontera entre lo jurídico y lo político, entre la convocatoria de sentencias existentes y la creación de nuevas normas. Como lo recuerda la SCC T-691/2012, "la Corte Constitucional se preocupó desde un inicio por mostrar de qué manera las discriminaciones estructurales siguen inmersas en las culturas dominantes de los distintos pueblos, comunidades y grupos sociales que habitan Colombia" (énfasis propio), con lo que se ubicó en el registro del voluntariado político para "mostrar" la existencia de discriminación estructural. Y la Corte es consciente de la dificultad de identificar este tipo de discriminaciones "naturalizadas en la vida diaria y casi invisibles para la mayoría de la sociedad” (SCC T-691/2012), que no pueden medirse con una prueba de igualdad (SCC T-969/2014) y que no son equivalentes a una suma de comportamientos particulares de exclusión (SCC C-671/2014).

Si la referencia a la discriminación estructural refleja una jurisprudencia “en proceso", esta se ve de manera clara en las prácticas administrativas, tal como se leen en el texto de la tutela. En este sentido, si bien es difícil para las juezas y los jueces “mostrar” la discriminación estructural, la propia sentencia nos muestra esta discriminación en acta. Las actividades de las administraciones públicas, tal como están restituidas en la sentencia, así como los mecanismos concretos del procedimiento jurídico de la acción de tutela, informan de manera muy empírica sobre las disfunciones institucionales ordinarias y la descalificación recurrente de la defensa de los derechos que contribuyen a la exclusión e inferiorización de ciertos sectores de la población. Una ilustración al respecto es 
ofrecida por el camino mismo de la tutela en la institución jurídica. En enero de 2014, la Corte Superior de Cartagena rechaza dos veces la acción de tutela, primero porque el primer magistrado solicitado era, él mismo, dueño de un terreno en Arroyo Grande; luego porque se reprochó a Edelmira Ortega de Marrugo no haber demostrado su condición de representante legal de los copropietarios de Arroyo Grande. Después de admitir la tutela, la Corte Superior de Cartagena niega las acusaciones que contiene. La demandante cuestiona esta decisión y envía su solicitud a la Corte Suprema de Justicia. Esta declara la nulidad de todo el procedimiento anterior y ordena reanudarlo desde el principio. La acción de tutela es remitida de nuevo a la Corte Superior de Cartagena, que niega también las peticiones de la demandante, quien una vez más cuestiona esta opinión y se dirige otra vez a la Corte Suprema; esta rechaza la tutela porque la demandante no ha agotado los otros mecanismos de defensa legal. Tales idas y vueltas administrativas duran todo el 2014. En marzo de 2015, la Corte Constitucional se hizo cargo del caso, relanzó el procedimiento legal (nuevos elementos de información, nuevas entrevistas con las administraciones implicadas, análisis del contexto histórico y de la situación de las poblaciones afrodescendientes) y este culminó en noviembre de 2016.

Además, a lo largo de las cien páginas del texto de la tutela, donde se describen las interacciones entre reclamantes y administraciones, aparece un conjunto de frases cortas, prácticas ordinarias, formas de interacción que, a través de su acumulación y su repetición, esbozan una lógica institucional de trato diferencial negativo: falta de responsabilidad o competencia de las administraciones, indiferencia frente a la incertidumbre legal, envío de las solicitudes de una administración a otra, argumento de falta de medios, respuestas que eluden las solicitudes, cuestionamiento del estatus de los denunciantes (origen étnico, representatividad). La acción de tutela en sí revela la dimensión empírica efectiva de la discriminación sistémica y la falta de respeto por los derechos, tanto en las prácticas de las administraciones públicas como en el procedimiento jurídico.

Esta situación cuestiona también el acceso al derecho, o más bien a los derechos, y la transición de un Estado de derecho a un "Estado de los derechos" (Baudot y Revillard 2015). El título heredado del siglo XIX, formalmente registrado ante las autoridades competentes, no parece ser prueba suficiente de la legalidad de la posesión de las tierras. Ha sido necesario que los demandantes, pero también la Corte Constitucional, movilizaran argumentos adicionales: el apoyo de una asociación negra (Fundación para el Desarrollo de las Comunidades Negras e Indígenas Afrodescendientes [Fundaconeafro]) y tres consejos 
comunitarios $^{18}$ para registrarse en la lógica multicultural; la referencia al estatus de "sujetos de especial protección constitucional, debido a la diversidad étnica y cultural” (SCC T-601/2016, “Consideraciones de la Corte Constitucional”, párr. 2), en el marco de la vulneración de los derechos relacionados con el conflicto y el desplazamiento forzado; la reivindicación de una identidad cultural, tradiciones y costumbres propias, de pertenencia a una comunidad y del vínculo ancestral con el territorio, con referencia a una lógica de etnicización de la alteridad. Esta estrategia de multiplicar los argumentos de justificación y reclamo probablemente responde en gran parte a la discriminación estructural experimentada por los demandantes y a las disfunciones administrativas de los procedimientos de control de propiedad. De hecho, es en calidad de sujeto de protección especial, no como descendiente de esclavos o como ciudadana, como Edelmira Ortega de Marrugo pudo iniciar el procedimiento de tutela.

Esta lógica de acción confirma la fragilidad del sistema jurídico colombiano que obliga a una persona a poseer un derecho de propiedad, ser descendiente de esclavo, miembro de una comunidad, poseer rasgos culturales específicos o ser víctima de desplazamiento forzado para ser atendida por las administraciones públicas. Además, relativiza la naturaleza innovadora del reconocimiento de reparaciones relacionadas con la esclavitud que se han hecho efectivas al movilizar también herramientas multiculturales. La Corte otorgó derechos de propiedad a los miembros de los tres consejos comunitarios, a pesar de que no aparecen como herederos de los 113 propietarios registrados en 1897 (SCC T-601/2016, “Consideraciones de la Corte Constitucional”, párr. 59). La lógica étnica (pertenecer a un consejo comunitario) tuvo prioridad sobre la lógica histórica (transmisión de un título de propiedad como descendientes de esclavos). De hecho, las numerosas resoluciones adoptadas por la Agencia Nacional de Tierras (2869 de 27 de junio de 2018, 2433 de 27 de febrero de 2019, 4100 de 12 de abril de 2019) para aclarar la situación ya no hacen referencia a una reparación relacionada con la esclavitud y los "esclavos”, reemplazados por la mención de consejos comunitarios y “comunidades étnicas afrodescendientes”. La sentencia cuestiona la efectividad del acceso a los derechos, facilitado por el reconocimiento de la diferencia e incluso las diferencias, pero también confrontado el riesgo de fragmentación del derecho - para grupos étnicos, personas desplazadas, víctimas, descendientes de esclavos-. Así mismo, muestra que la cuestión de las reparaciones por la esclavitud no es legítima y que se ha abandonado gradualmente en favor de

18 Creados en el marco de la Ley 70 de 1993, los consejos comunitarios son entidades administrativas y jurídicas que permiten la gestión de los territorios colectivos por parte de las comunidades afrodescendientes. 
herramientas más clásicas del derecho individual de propiedad o del derecho étnico colectivo.

\section{Conclusiones}

Varios estudios han demostrado que uno de los desafíos del activismo legal contemporáneo se encuentra fuera de los tribunales, con la apropiación de las decisiones judiciales y los textos legales por parte de los actores directamente interesados y el resto de la sociedad (Rodríguez y Rodríguez 2010). En este sentido, la efectividad social de las dos sentencias analizadas es bastante limitada. La SCC C-931/09 sobre la Ley de 1851 provocó un debate contradictorio en torno a la abolición y sus consecuencias e hizo posible recordar las desigualdades y la marginación que afectan a las poblaciones afrodescendientes. Sin embargo, la solicitud de inconstitucionalidad de la ley de abolición fue rechazada. Por su parte, la SCC T-601/2016 sobre Arroyo Grande es una victoria legal para la demandante y un cuestionamiento directo a la inacción del Estado. Sin embargo, demuestra ser un verdadero rompecabezas administrativo, jurídico y político ${ }^{19}$ y plantea la cuestión del acceso a un derecho que, al tiempo que se convierte en plural (derecho de los afrocolombianos, derecho de los descendientes de esclavos, derecho de las víctimas del conflicto, etc.), también sigue siendo incierto.

¿Son las reparaciones una extensión de las políticas multiculturales introducidas en la década de los noventa? ¿O una ruptura que denuncia los límites del multiculturalismo? Las dos sentencias estudiadas se refieren a la región Caribe - la SCC C-931/2009 es otorgada por un abogado de Barranquilla; la SCC T-601/2016 trata sobre tierras entre Barranquilla y Cartagena-que durante mucho tiempo permaneció fuera de las dinámicas multiculturales relacionadas con el Pacífico ${ }^{20}$. Por lo tanto, aparecen nuevas prácticas (movilización del derecho,

19 Sobre las dificultades para identificar a los propietarios y delimitar las tierras, ver Agencia Nacional de Tierras (2019a). Como consecuencia de la SCC T-601/2016, esta entidad ha sido encargada de verificar la validez de los títulos de propiedad, identificar las tierras baldías bajo control del Estado y establecer los límites geográficos de los terrenos (Agencia Nacional de Tierras 2019b). La sentencia también hizo un llamado a manifestación pública para identificar potenciales propietarios/as desconocidos/as y encargó a la Agencia Nacional de Tierras de validar o no los títulos de propiedad.

20 Recordemos que la Ley 70 de 1993 está dirigida a las poblaciones del Pacífico identificadas por sus "prácticas tradicionales de producción". Se puede aplicar en "otras zonas del país", que tienen las mismas características geográficas (tierra baldía, áreas rurales, estar ubicadas a lo largo de los ríos) y culturales (prácticas tradicionales de producción). Estas condiciones, de hecho, han limitado en gran medida el uso de esta ley para la tenencia de la tierra en el 
solicitudes de la Corte Constitucional), nuevas demandas (legado de la esclavitud, discriminación estructural), nuevos actores (abogados, jueces, Corte Constitucional, ONG expertas en derecho, en lugar de los movimientos étnicos y las organizaciones de base) y nuevos contextos locales (Caribe) que reflejan la necesidad de inventar repertorios de acción que vayan más allá del marco multicultural. Las reflexiones sobre el territorio, la identidad, el origen étnico, la cultura o la categoría afrocolombiano, que marcaron la década de los noventa, dan paso a reclamos sobre descendientes de esclavos o incluso esclavizados ${ }^{21}$, víctimas, justicia transicional, discriminación o memoria. Las movilizaciones políticas de asociaciones de base se transforman en reivindicaciones por los derechos lideradas por los juristas cuyo compromiso también tiene una dimensión política; el enfoque cultural basado en la disciplina antropológica deja lugar a una redefinición de la relación entre pasado y presente y la reescritura de la historia; la lógica de acción centrada en el reconocimiento de la diferencia se complementa con una denuncia del racismo 22 .

Sin embargo, la demanda de reparaciones se origina indudablemente en el marco multicultural abierto en la década de los noventa que hizo pública y legítima la cuestión del reconocimiento de las diferencias, permitió el surgimiento de una nueva generación de actores autodefinidos como afrocolombianos y estableció las normas legales movilizadas por las solicitudes de reparación. De hecho, el marco multicultural se considera obvio en las sentencias de la Corte Constitucional que toman como punto de partida la existencia no problematizada de un grupo étnico afrocolombiano. En este sentido, mucho más que un abandono, observamos una reificación de este marco. Además, más que una sustitución de las categorías de afrocolombiano y afrodescendiente por las de descendiente de esclavo y esclavizado, más que una transición de lo cultural a lo histórico, de lo antropológico a lo jurídico, estamos presenciando una superposición de diferentes registros. Esto autoriza una mayor capacidad de agencia, pero también tiende a condicionar el acceso al derecho a múltiples pertenencias, definidas en términos

Caribe (ver Durán 2007 y la obtención tardía de un título de propiedad colectiva en las islas del Rosario en 2014).

La SCC C-931/2009 utiliza el término persona esclavizada y no esclavo o esclava.

Ver, por ejemplo, las actividades del Observatorio de Discriminación Racial de la Universidad de los Andes en http://www.odracial.org/ o el proyecto de investigación Lapora en la Universidad de Cambridge sobre antirracismo en https://www.lapora.sociology.cam.ac.uk/ 
de identidad (afrocolombiana, indígena), de género, de generación y ahora de estatus político (víctima) y herencia histórica (descendiente de esclavos) ${ }^{23}$.

Al mismo tiempo, este acceso a los derechos pasa por una competencia experta cada vez más necesaria - la solicitud de inconstitucionalidad de la ley de abolición es impulsada por un abogado; las ONG de defensa de los derechos humanos ahora desempeñan un papel de intermediarias-y procedimientos legales largos y complejos —el caso de Arroyo Grande se inició en enero de 2014, ha pasado por muchas entidades legales y administrativas y aún no ha sido resuelto-. Es importante subrayar que la solicitud de inconstitucionalidad, realizada de forma aislada por un abogado de Barranquilla, no ha sido retomada por las organizaciones afrocolombianas ${ }^{24}$. Otra pista queda abierta a futuras investigaciones: el papel de la subjetividad, de las trayectorias personales y profesionales, de las relaciones de poder de y entre quienes ejercen el derecho, sea como litigantes o administradores de justicia (Cuéllar 2008). Parece así que la fábrica del derecho responde más a los intereses de los magistrados (Corte Constitucional como foro político, introducción del tema de la discriminación estructural, rivalidades personales y profesionales) que a las necesidades de la ciudadanía.

\section{Referencias}

Agencia Nacional de Tierras. 2019a. "Agencia de Tierras denuncia intentos de saboteo a proceso de clarificación de caso Arroyo Grande”. https://www.agenciadetierras.gov. co/2018/08/24/agencia-de-tierras-denuncia-intentos-de-saboteo-a-proceso-de-clarificacion-de-caso-arroyo-grande/

Agencia Nacional de Tierras. 2019b. Informe de visita técnica de georreferenciación de la reconstrucción histórica cartográfica del predio de mayor extensión conocido como la antigua hacienda de campo nombrada Púa, y el predio Púa (lote \#2 de la antigua "Hacienda Púa") y replanteo del polígono definido para el predio Hacienda Arroyo Grande. Cartagena: Ministerio de Agricultura de Colombia. https://www.agenciadetierras.gov.co/wp-content/uploads/2019/05/SEJUT-F-001-PACLA_HACIENDA-DE-CAMPO-PUA_VF-fusionadofirmado.pdf

23 Y, más recientemente, de campesinos/as (Renaf 2018) y de naturaleza (ver la SCC T-622/2016, que reconoce el río Atrato, en la región del Pacífico colombiano, como sujeto de derechos).

24 El coloquio "De reparaciones colectivas a reparaciones históricas para el pueblo afrodescendiente en Colombia" - realizado en marzo de 2017 en Cali- ilustra esta situación: las actas no mencionan la iniciativa de Antonio Eduardo Bohórquez Collazos ni las referencias a la legitimidad de las reparaciones en la sentencia o en el salvamento de voto (Codhes 2017). 
Audoin-Rouzeau, Stéphane. 2016. "Chercheurs dans le prétoire. Retour sur le procès Simbikangwa (2014). Un dialogue magistrat-historien”. Grief 3: 175-182.

Baudot, Pierre-Yves y Anne Revillard, dirs. 2015. L'État des droits: politique des droits et pratiques des institutions. París: Presses de Sciences Po.

Bocarejo, Diana. 2011. "Dos paradojas del multiculturalismo colombiano: la espacialización de la diferencia indígena y su aislamiento político”. Revista Colombiana de Antropología 47 (2): 97-121. https://doi.org/10.22380/2539472X.959

Cepeda Espinosa, Manuel José. 2004. “La defensa judicial de la Constitución”. En Fortalezas de Colombia, editado por Fernando Cepeda Ulloa, 145-211. Bogotá: Ariel; Banco Interamericano de Desarrollo.

Codhes (Consultoría para los Derechos Humanos y el Desplazamiento). 2017. Informe. Retos para una agenda nacional e internacional de reparaciones para el pueblo y comunidades afrodescendientes en Colombia. Bogotá: FOS Colombia; Observatorio de Reparación Colectiva; Codhes. http://convergenciacnoa.org/wp-content/uploads/2018/08/Taller-RC_VerVIII.pdf

Commaille, Jacques y Laurence Dumoulin. 2009. "Heurs et malheurs de la légalité dans les sociétés contemporaines. Une sociologie politique de la ‘judiciarisation’”. L’Année Sociologique 59: 63-107. https://doi.org/10.3917/anso.091.0063

Cuéllar Vázquez, Angélica. 2000. La justicia sometida: análisis sociológico de una sentencia. Ciudad de México: FCPyS; Miguel Ángel Porrúa.

—. 2008. Los jueces de la tradición: un estudio de caso. Ciudad de México: Sitesa; UNAM.

Dunezat, Xavier y Camille Gourdeau. 2016. "Le racisme institutionnel: un concept polyphonique”. Migrations Société 163 (1): 13-32. https://doi.org/10.3917/migra.163.0013

Dupret, Baudoin. 2006. Droit et sciences sociales. París: Armand Colin.

Durán Bernal, Carlos Andrés. 2007. ¿Es nuestra isla para dos?: conflicto por el desarrollo y la conservación en islas del Rosario, Cartagena. Bogotá: Universidad de los Andes/Ceso/Departamento de Antropología.

Epp, Charles R. 2013. La revolución de los derechos: abogados, activistas y cortes supremas en perspectiva comparada. Buenos Aires: Siglo XXI.

Feoli, Marco V. 2016. "Judicialización de la política y activismo judicial: una aproximación a América Latina”. Revista Latinoamericana de Derechos Humanos 27 (1): 75-98. https://doi. org/10.15359/rldh.27-1.4

Garapon, Antoine. 2008. Peut-on réparer l'histoire? Colonisation, esclavage, Shoah. París: Odile Jacob.

Herrera, Carlos Miguel, dir. 2015. Le constitutionnalisme latino-américain aujourd'hui: entre renouveau juridique et essor démocratique? París: Kimé.

Hoffmann, Odile. 2004. Communautés noires du Pacifique colombien: innovations et dynamiques ethniques. París: Karthala; IRD.

Israël, Liora. 2008. “Question(s) de méthode. Se saisir du droit en sociologue”. Droit et Société 69-70: 381-395. https://doi.org/10.3917/drs.069.0381 
Lara Largo, Sofía. 2016. "Estrategias de apropiación territorial en un contexto de relación interétnica en Guamal, Caldas”. Revista Colombiana de Antropología 52 (1): 117-138. https:// doi.org/10.22380/2539472X5

Latour, Bruno. 2002. La fabrique du droit: une ethnographie du Conseil d'Etat. París: Editions la Découverte.

Lemaitre Ripoll, Julieta. 2009. El derecho como conjuro: fetichismo legal, violencia y movimientos sociales. Bogotá: Siglo del Hombre; Universidad de los Andes.

López, Óscar, Tulio Rojas, Carlos Duarte, Grace Boffey y Dayver Betancourt. 2019. Análisis de la política pública de reparación a las víctimas pertenecientes a comunidades étnica y culturalmente diferenciadas. Bogotá: Universidad Libre.

Molinares Hassan, Viridiana. 2013. "Afrodescendientes: otro caso de garantismo de la Corte Constitucional colombiana”. Vniversitas 62 (127): 189-221. https://doi.org/10.11144/Javeriana.VJ127.aocg

Mosquera, Claudia, Mauricio Pardo y Odile Hoffmann, eds. 2002. Afrodescendientes en las Américas: trayectorias sociales e identitarias. 150 años de la abolición de la esclavitud en Colombia. Bogotá: Universidad Nacional de Colombia; ICANH; IRD.

Mosquera Rosero-Labbé, Claudia y Luiz Claudio Barcelos, eds. 2007. Afro-reparaciones: memorias de la esclavitud y justicia reparativa para negros, afrocolombianos y raizales. Bogotá: Universidad Nacional de Colombia/Observatorio del Caribe Colombiano.

Mosquera Rosero-Labbé, Claudia, Agustín Laó-Montes y César Rodríguez Garavito, eds. 2010. Debates sobre ciudadanía y políticas raciales en las Américas negras. Bogotá: Universidad Nacional de Colombia; Universidad del Valle.

Mosquera Rosero-Labbé, Claudia y Ruby Esther León Díaz, eds. 2009. Acciones afirmativas y ciudadanía diferenciada étnico-racial negra, afrocolombiana, palenquera y raizal: entre bicentenarios de las independencias y Constitución de 1991. Bogotá: Universidad Nacional de Colombia.

Mosquera Rosero-Labbé, Claudia, Ruby Esther León Díaz y Margarita María Rodríguez Morales, eds. 2009. Escenarios post-Durban: para pueblos y personas negras, afrocolombianas, raizales y palenqueras. Bogotá: Universidad Nacional de Colombia.

Ogletree, Charles J., Jr. 2003. "The Current Reparations Debate”. U.C. Davis Law Review 36 (5): 1051-1072.

Renaf (Red Nacional de Agricultura Familiar). 2018. "La Declaración de los Derechos de los Campesinos sí podría proteger al campesinado colombiano”. http://agriculturafamiliar. co/la-declaracion-de-derechos-campesinos-si-podria-proteger-al-campesinado-colombiano/

Rodríguez Garavito, César y Diana Rodríguez Franco. 2010. Cortes y cambio social: cómo la Corte Constitucional transformó el desplazamiento forzado en Colombia. Bogotá: DeJusticia.

Urrutia, Alonso. 2019. “Que España se disculpe por las matanzas: AMLO”. La Jornada, 25 de marzo. https://www.jornada.com.mx/ultimas/politica/2019/03/25/amlo-pide-disculpapublica-de-rey-de-espana-a-500-anos-de-la-conquista-4821.html 